\title{
Electrical activity across human foetal small intestine associated with absorption processes
}

\author{
R. J. LEVIN, ${ }^{1}$ O. KOLDOVSKÝ, J. HOŠKOVÁ, V. JIRSOVÁ, AND J. UHER \\ From the Institute of Physiology, Laboratory of Developmental Nutrition, Czechoslovak Academy \\ of Sciences, the Institute for the Care of Mother and Child, and the Institute for \\ Postgraduate Education of Physicians Obstetric Clinic, Prague, Czechoslovakia
}

An electrical potential difference can be measured across the wall of animal and human small intestine, the polarity being serosa positive to mucosa. When actively transferred hexoses or amino acids are added to the fluid bathing the intestinal mucosal surface, a rapid increase in this endogenous or basal transmural potential difference is observed, i.e. an hexose or amino acid transfer potential difference (Schachter and Britten, 1961, in the rat; Barry, Dikstein, Matthews, Smyth, and Wright, 1964, in the rat; Schultz and Zalusky, 1965, in the rabbit; Levin, 1966, in the bullfrog; Grady, MacGaffey, Moore, and Chalmers, 1966, in man). Although there is still doubt as to the exact nature of the electrogenic mechanisms in rat jejunum (Barry, Smyth, and Wright, 1965) studies on rabbit ileum indicate that the active transfer of hexose or amino acid is linked with an increased movement of sodium ions which generates the transfer potential difference (Schultz and Zalusky, 1965).

All studies on the electrogenic hexose and amino acid transfer systems in mammals have been conducted on intestine from mature animals. No data are available on the electrogenicity of transfer mechanisms for amino acids and hexoses present in the intestines of foetal animals (Wilson and Lin, 1960) or foetal humans (Koldovský, Heringová, Jirsová, Jirásek, and Uher, 1965). Hudson and Levin (1966) have recently studied the ontogeny of electrical activity across the small intestine in vitro during the development of the chick. They showed that the active hexose transfer system in the chick embryonic intestine (Holdsworth and Wilson, 1967) was electrogenic, for only actively transported sugars gave transfer potentials. In this paper the ontogeny of electrical activity across small intestine from human foetuses has been studied using a similar in vitro technique. Experiments have also been undertaken to investigate the influence of some amino acids on

${ }^{1}$ Address requests for reprints to R. J. Levin, Department of Physio-
logy, University of Sheffield, Sheffield, Yorkshire, England. the electrical activity across the human foetal intestine.

\section{METHODS}

Foetuses were removed by the vaginal route from healthy women for social reasons. Details of anaesthesia are to be found in a previous paper (Koldovský et al., 1965). Immediately on removal of the foetus the whole alimentary tract (if this was possible) was dissected and placed in a test tube containing a phosphate buffer (Krebs, 1933) surrounded by melting ice. Within a few minutes it was taken to the laboratory and placed on a glass plate. The underside of the plate was in contact with melting ice while the top was moistened with phosphate buffer. The parts of the alimentary canal were identified. In foetuses older than 14 weeks the ileum could be distinguished because it contained meconium. Everted sacs of jejunum and ileum $(0.5$ to $1 \mathrm{~cm})$ were made by everting the intestine over cannulae formed by pulling heated plastic tubing. One end of the intestine was tied to the cannula while the other was closed by a ligature attached to a light glass weight to facilitate vertical suspension of the sacs in the incubating buffer. The sacs were filled with 0.1 to $0.5 \mathrm{ml}$ phosphate buffer and were suspended in $25 \mathrm{ml}$ of the same solution gassed with $\mathrm{O}_{2}$ at $38^{\circ} \mathrm{C}$ in an apparatus very similar to that of Barry et al. (1964). The electrical potential difference across the wall of the sac was recorded by two agar salt bridges (3\% agar in $1 \mathrm{M}$ $\mathrm{KCl}$ ) made by filling plastic tubing (Portex 50) with the agar solution. The bridges were placed in contact with the mucosal and serosal solutions. These bridges led to two matched calomel cells which were connected across either a Vibron electrometer (model 33B2) or a Cary 31B electrometer (Applied Physics Corp.). The outputs of both electrometers were connected to recording potentiometers; the Vibron was connected to a Heathkit (U.S.A.), while the Cary was connected to a M.A.W. recorder (Magdeberg, E. Germany). All electrical potentials were corrected for calomel cell or electrode asymmetry by recording the potential difference when both bridges were in the mucosal bathing medium. This small potential difference $(<0.5 \mathrm{mV})$ was subtracted from all the recorded transmural potential differences. The potential difference in the absence of any exogenous substrate is 
called the 'endogenous' potential difference. The increase in the potential difference caused by the addition of actively transferred hexoses or amino acids to the mucosal fluid is called the 'hexose or amino acid transfer potential difference'. Any decrease in the endogenous or basal potential difference caused by the addition of solutes to the mucosal fluid is called an 'osmotic induced potential difference'. In most cases potential differences were measured five minutes after setting up and five minutes after the addition of solutes to the mucosal fluid. In a few very young embryos, the small intestine was too fragile to evert. As the wall was thin, adequate oxygenation of the mucosa could take place by diffusing oxygen through the serosal muscle layers of the non-everted sac. The endogenous potential difference could thus be measured in this type of preparation. Changing the mucosal fluid in these non-everted sacs was very difficult and damage to the mucosa would often result. Because of this difficulty, hexose transfer potentials were obtained in such cases by using two sacs of non-everted intestine taken from the same region (about $0.5 \mathrm{~cm}$ long) and incubated at the same time. One was filled with the phosphate buffer, the other with buffer containing glucose. The glucose transfer potential difference was obtained by subtracting the endogenous potential difference of the former sac from that measured in the latter.

The presumptive ages of the various foetuses were calculated from the last menses recorded by the mothers. The correspondence between the presumptive and the real age was checked by observation of the foetal anatomical development and corrections of the foetal age were made using the criteria of Potter (1952). Chemicals used were D-glucose (Lachema N.P., Czechoslovakia), L-alanine, D-alanine, D-xylose, $\alpha$-methyl glucoside, D-fructose and phlorrhizin (British Drug Houses), and mannitol (May \& Baker).
RESULTS

The endogenous potential difference across everted foetal jejunum (i.e. potential difference in the absence of any exogenous substrate) was found to be small, never greater than $1.5 \mathrm{mV}$. The initial polarity was always serosa positive to mucosa. On the addition of glucose to the mucosal fluid an increase in this potential difference occurred, i.e. an hexose transfer potential difference was generated. Figure 1A shows the glucose potential difference dose response curves obtained in four foetal jejuna of ages varying from 14 to 21 weeks. The mechanism generating the potential difference appears to be saturated between 7 and $14 \mathrm{mM}$ glucose. Further addition of glucose (28 $\mathrm{mM}$ ) caused a large decrease in the potential difference. This decrease is due partly to the saturation of the potential difference generating site and partly to the osmotic effects of the glucose load which was added only to the mucosal fluid. Corrections for the osmotic effects were obtained by measuring the decreases in potential difference (i.e. osmotic induced potentials) that occurred when an equivalent amount of a non-absorbed solute (mannitol) was added to the mucosal fluid bathing an everted jejunum from a 15.5 week foetus. The osmotic induced potentials obtained with mannitol were $-0.55 \mathrm{mV}$ at $3.5 \mathrm{mM},-0.65 \mathrm{mV}$ at $7 \mathrm{mM}$, $-1.1 \mathrm{mV}$ at $14 \mathrm{mM}$, and $-1.7 \mathrm{mV}$ at $28 \mathrm{mM}$ mannitol. These values agreed surprisingly well with values obtained using the small intestine of the young (5-10-day-old) and adult rats (Levin, Koldov-

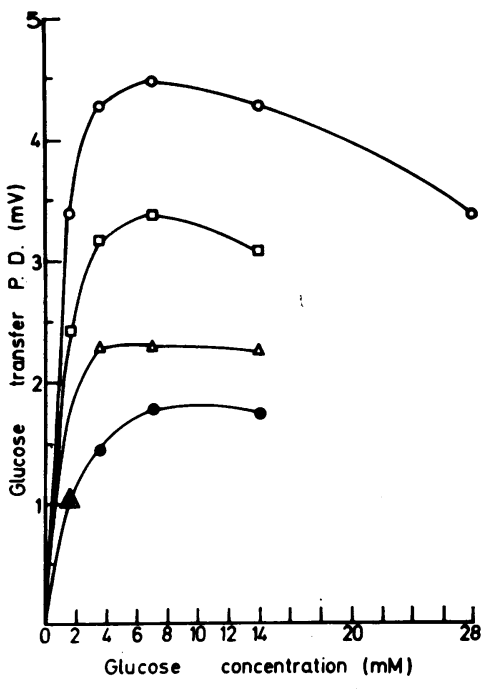

FIG. 1A.

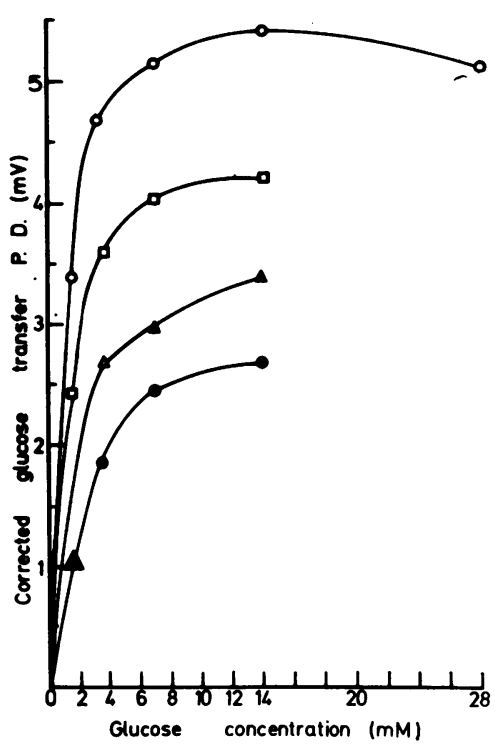

FIG. 1. In A the results from four everted foetal jejuna incubated in Krebs phosphate saline are plotted without correction for the osmotic effects of the mucosal glucose load. The ages of the foetal intestines are: 14.5 weeks, $\triangle 15$ weeks, $\bigcirc 16.5$ weeks, and $\square$ 21 weeks. In $B$ the potentials for the 3.5, 7, 14, and $28 \mathrm{mM}$ addition of glucose have been corrected for the osmotic effect of the mucosal glucose by adding on to each transfer potential difference the osmotic-induced potential difference obtained when a similar concentration of mannitol was added to the mucosal fluid bathing an everted jejunum from a $15 \cdot 5$ week foetus. 
ský, and Hošková, unpublished observations). The osmotic induced potentials caused by mannitol were added onto the hexose transfer potentials caused by equivalent molarity of glucose, recorded in Figure 1A. These corrected data were used for doseresponse curves of Figure 1B.

Even when the hexose transfer potentials were corrected for the osmotic effect, the potential generating mechanism still shows evidence of saturation at the higher glucose loads. The reciprocals of the corrected glucose transfer potential difference from Fig. 1B, when plotted against the reciprocal of the concentration of glucose by the technique of Lineweaver and Burk (1934), allowed an approximation of the 'apparent $\mathrm{K}_{\mathrm{m}}$ ' of glucose for the potential difference generating mechanism to be obtained. The values obtained were $5 \mathrm{mM}$ (14.5 weeks), $7.4 \mathrm{mM}$ (15 weeks), $1.2 \mathrm{mM}$ (16.5 weeks), and $1.8 \mathrm{mM}$ (21 weeks).

CHARACTERISTICS OF THE HEXOSE TRANSFER POTENTIAL DIFFERENCE A number of experiments were undertaken to characterize the hexose transfer potential difference. The glucose transfer potential difference was immediately abolished in four jejunal sacs by small doses of phlorrhizin when this was applied to the mucosal solution $\left(5 \times 10^{-4} \mathrm{M}\right)$ but the endogenous potential difference was unaffected by this concentration of inhibitor. The actively transported but non-metabolized hexose $\alpha$-methyl glucoside also gave a hexose transfer potential difference when added to the mucosal solution $(7 \mathrm{mM})$ but the potentials obtained were smaller than that for equimolar glucose. D-xylose (7 $\mathrm{mM})$ and D-fructose $(7 \mathrm{mM})$, on the other hand, depressed the endogenous potential difference, both causing a small osmotic-induced potential difference (Table I). The effects of the addition of sucrose and lactose were tested on a jejunum from a 14.5 week foetus. This preparation responded to addition of glucose $(7 \mathrm{mM})$ with a glucose transfer potential difference of $1.5 \mathrm{mV}$. Lactose $(3.5 \mathrm{mM})$ caused a small depression of the endogenous potential difference (osmotic potential difference of $-0.4 \mathrm{mV}$ ) while an equimolar addition of sucrose (after washing out the lactose) caused a small increase of $0.6 \mathrm{mV}$ which slowly decayed to $0.4 \mathrm{mV}$ after one minute. A larger sucrose addition $(7 \mathrm{mM})$ caused an increase in potential difference of $0.5 \mathrm{mV}$ that again slowly decayed.

CHANGES IN THE ENDOGENOUS AND HEXOSE TRANSFER POTENTIAL DIFFERENCES WITH INCREASING FOETAL AGE The endogenous and the glucose transfer potential differences were measured across everted jejuna removed from 11 foetuses of varying gestational ages (12 to 21 weeks). The endogenous potentials were measured some five minutes after incubation and then glucose $(7 \mathrm{mM})$ was added to the mucosal fluid and the hexose transfer potential difference recorded five minutes later. Both sets of data are shown graphically in Figure 2. The upper graph contains the glucose transfer potentials while the lower graph contains the endogenous potentials.

EFFECTS OF AMINO ACIDS The effects of the addition of $\mathrm{D}$ - and L-alanine to the mucosal fluid bathing a number of everted jejuna were observed (Table I). L-alanine (actively transferred) gave an immediate increase in the endogenous potential difference, i.e. an amino acid transfer potential difference. Dalanine (non-actively transferred) caused a small decrease, presumably because it acted as an osmotic load and caused a small osmotic induced potential difference. If glucose was added to the mucosal fluid to generate the glucose transfer potential difference the addition of L-alanine $(7 \mathrm{mM})$ still increased the transmural potential difference, while if the amino acid was added first and then the glucose load similar hexose and amino acid transfer potentials were

TABLE I

EFFECTS OF VARIOUS SUGARS AND AMINO ACIDS ON THE POTENTIAL DIFFERENCE ACROSS SIX EVERTED JEJUNA FROM HUMAN FOETUSES OF VARYING AGE ${ }^{1}$

\begin{tabular}{|c|c|c|c|c|c|c|}
\hline \multirow{2}{*}{$\begin{array}{l}\text { Foetal } \\
\text { Age } \\
(w k)\end{array}$} & \multicolumn{4}{|c|}{$\begin{array}{l}\text { Sugar Transfer Potential Difference } \\
(m V)\end{array}$} & \multicolumn{2}{|c|}{$\begin{array}{l}\text { Amino Acid Transfer Potential } \\
\text { Difference }(m V)\end{array}$} \\
\hline & D-Glucose & D-Xylose & D-Fructose & a-Methyl Glucoside & L-alanine & D-alanine \\
\hline $\begin{array}{l}12 \\
13 \\
14 \\
14 \cdot 5 \\
15 \\
15\end{array}$ & $\begin{array}{l}0.5 \\
1.9 \\
1.3 \\
2.3 \\
2.3 \\
1.9\end{array}$ & $\begin{array}{c}-\overline{0.1} \\
\overline{-} \\
-\overline{0.3} \\
-\end{array}$ & $\begin{array}{c}\overline{-} \\
-\overline{2} \\
- \\
- \\
-\end{array}$ & $\begin{array}{l}\overline{-} \\
\frac{0 \cdot 6}{1 \cdot 1} \\
-\end{array}$ & $\begin{array}{l}1.0 \\
1.1 \\
1.0 \\
1.5 \\
1.1 \\
1.3\end{array}$ & $\begin{array}{c}-0.1 \\
-0.1 \\
-\overline{0.2} \\
-0.2 \\
-\end{array}$ \\
\hline
\end{tabular}

${ }^{1}$ Each solute was added to the mucosal fluid to give a concentration of $7 \mathrm{mM}$. The potential differences were measured five minutes after the addition and are uncorrected for osmotic effects. 

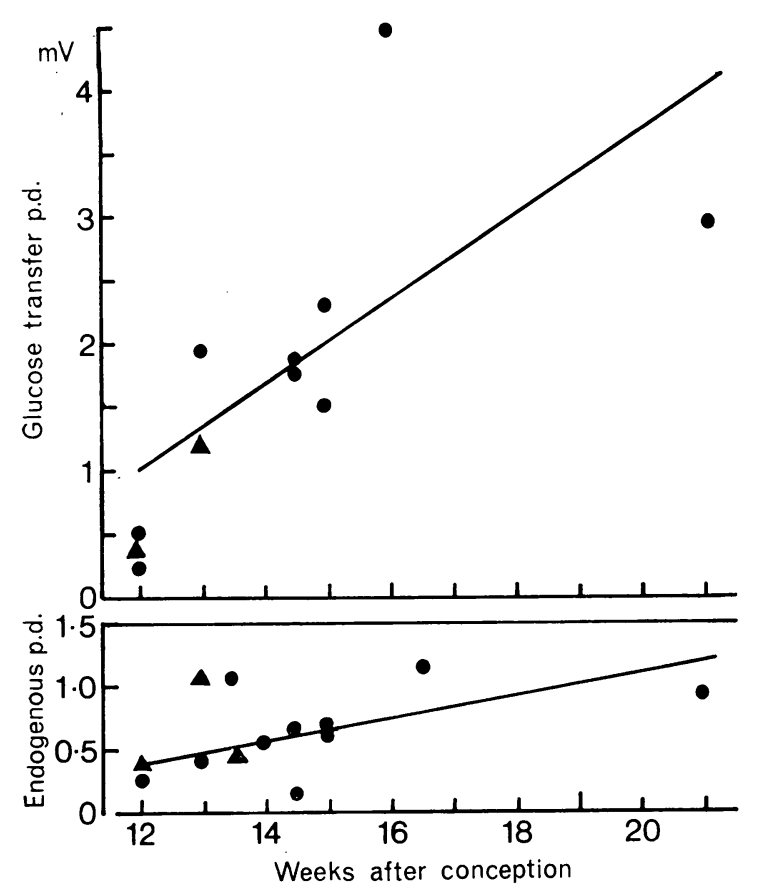

FIG. 2. The glucose transfer (upper graph) and the endogenous potential difference (lower graph) across human foetal jejuna incubated at $38^{\circ} \mathrm{C}$ in phosphate saline gassed with oxygen. The glucose transfer potentials were measured five minutes after addition of glucose $(7 \mathrm{mM})$ and are uncorrected for osmotic effects. The regression lines were calculated with data obtained from everted jejuna (O) only (10 foetuses). Data from some non-everted jejuna ( $\mathbf{\Delta})$ have been included on the graph for comparative purposes. In the upper graph the non-everted potential difference plotted on week 12 was obtained from one of the foetal intestines as an everted sac but the non-everted value for week 13 was from a separate foetus. In the lower graph, everted and non-everted sacs were made from the same foetal intestine at week 12 and week 13.5 while the value at week 13 was from a separate foetus. In a number of cases the plotted points from everted sacs represent the mean of two measurements made from adjacent sacs of intestine removed from the same foetus. Thus in the upper graph, one of the values for weeks 12,14.5, and 15 is a mean from duplicate sacs as is that for week 21. Similarly, in the lower graph, the values for weeks 15 and 21 come from duplicate sacs while one of the two values at week 14.5 is also a mean from duplicate sacs. The correlation coefficient for the glucose transfer potential difference against foetal age was $0.73(p<0.02)$ while that for the endogenous potential difference was $0.54(p<0 \cdot 1)$.

observed. The glucose and alanine transfer potentials generated in both cases were of similar magnitude to those generated when either compound was added alone.
EFFECTS OF ANOXIA ON THE ENDOGENOUS AND GLUCOSE TRANSFER POTENTIAL DIFFERENCES The effects of anoxia $\left(\mathrm{N}_{2}\right.$ gassing of the buffer) were tested on both the endogenous and hexose transfer potential differences in two foetal jejuna. In the first intestine (16.5 weeks) the endogenous potential difference fell from $1.7 \mathrm{mV}$ to $1.2 \mathrm{mV}$ after 10 minutes of anoxia. The addition of $7 \mathrm{mM}$ glucose in $\mathrm{O}_{2}$ gave a hexose transfer potential difference of $2.3 \mathrm{mV}$ while the addition of the same amount of glucose after 10 minutes of $\mathrm{N}_{2}$ gave $1.8 \mathrm{mV}$, a small decrease of about $22 \%$. In the second intestine (15.5 weeks) the initial endogenous potential difference in $\mathrm{O}_{2}$ was $0.8 \mathrm{mV}$ and the hexose transfer potential difference after the addition of $7 \mathrm{mM}$ glucose was $1.8 \mathrm{mV}$. Similar values for $\mathrm{N}_{2}$ were $0.35 \mathrm{mV}$ and $2.4 \mathrm{mV}$ respectively.

EFFECTS OF LOWERING THE MUCOSAL $\mathrm{NaCl}$ CONCENTRATION ON THE ENDOGENOUS AND GLUCOSE TRANSFER POTENTIAL DIFFERENCES The effects of lowering the mucosal $\mathrm{NaCl}$ concentration on the endogenous and glucose transfer potential differences across a number of foetal jejuna were observed. The osmotic balance of the mucosal solution was made up with isotonic mannitol. The small endogenous potential difference of all the sacs (serosa positive to mucosa) reversed on application of the first solution of lowered $\mathrm{NaCl}$ concentration (approximately $86 \mathrm{mEq} \mathrm{Na}{ }^{+} /$litre). Solutions of lower $\mathrm{NaCl}$ concentrations increased the negativity of the serosal solution (Figure 3). However, the lowest $\mathrm{NaCl}$ concentration did not increase the negativity of the serosal solution in three of the four intestines studied. Only with the data from the 15 -week foetal intestine was a straight line obtained when the endogenous potential difference was plotted against $\log \mathrm{Na}$ concentration of the mucosal fluid, the other jejuna gave curvilinear plots. The intestine was not damaged by the low $\mathrm{NaCl}$ solutions because on returning the sacs to buffer of normal sodium chloride composition they gave normal glucose transfer potentials on the addition of $7 \mathrm{mM}$ glucose to the mucosal solution. The glucose transfer potential difference was obtained at each concentration of mucosal sodium chloride by adding glucose $(7 \mathrm{mM})$ to the mucosal solution five minutes after the sac had been in contact with the new sodium chloride concentration (Figure 4). The potentials were then measured five minutes after the addition of the glucose. Although there was considerable scatter these glucose transfer potentials did not appear to be lowered by lowering the sodium chloride concentration.

ELECTRICAL ACTIVITY ACROSS THE FOETAL ILEUM Jirsová, Koldovský, Heringová, Hošková, Jirásek, 


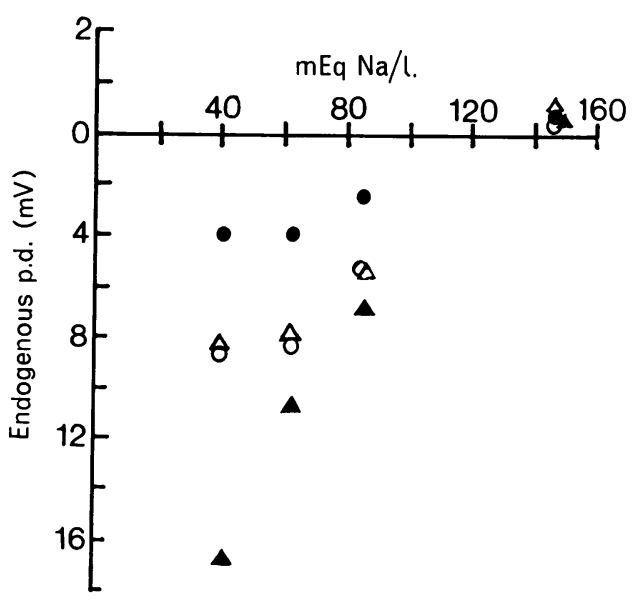

FIG. 3. The effect of changing the mucosal sodium chloride concentration on the endogenous potential difference across everted jejuna of human foetal small intestine. The osmotic balance of the phosphate buffer was made up with isotonic mannitol. The data represent results from four separate intestines. The open circles $(\bigcirc)$ are from a 13-week, the solid circles $(\bigcirc)$ from a 14-week, open triangles $(\triangle)$ from

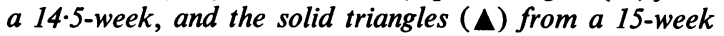
foetus.

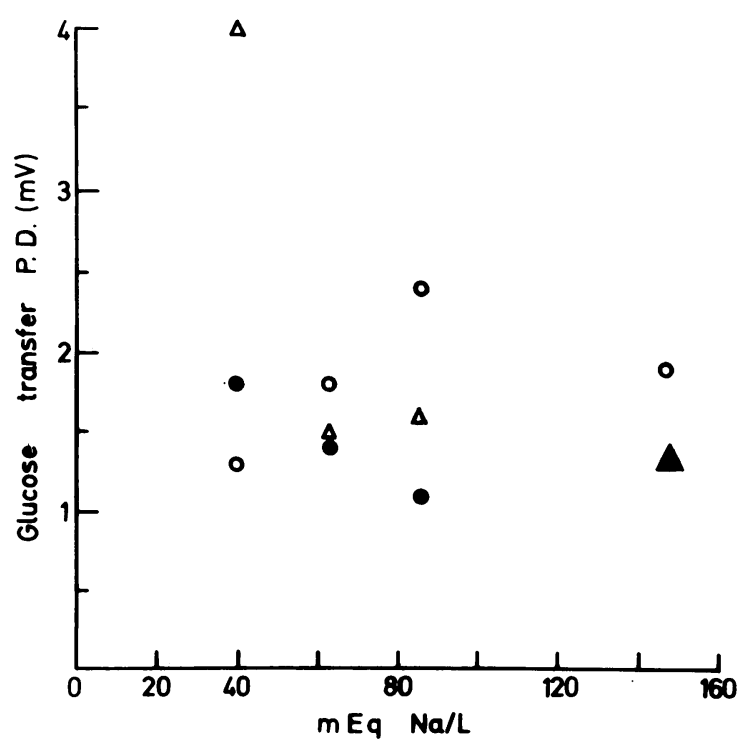

FIG. 4. The effect of changing the mucosal sodium chloride concentration on the glucose transfer potential difference evoked by the addition of glucose $(7 \mathrm{mM})$ to the mucosal fluid. The osmotic balance of the fluid was made up with isotonic mannitol. The data were obtained from three of the intestines used in Figure 3. and Uher (1966) reported that there was a distinct difference in the glucose transferring abilities of the human foetal ileum and jejunum. It was thus of some interest to see whether the ileum possessed electrogenic hexose and amino acid transferring mechanisms. The data obtained from five foetal ilea are collected in Table II together with data obtained in ilea removed from children and adults at operation. The ilea from children were removed at operations for the manufacture of ileal loops at the Children's Hospital, Sheffield, while the data from adult ilea are from the recent abstract of Grady et al. (1966). It should be noted that both the children's and the adult intestines were incubated in bicarbonate saline and were mounted in vitro as planar sheets between two flux chambers. The foetal intestines were everted sacs incubated in phosphate saline.

\section{TABLE II}

POTENTIAL DIFFERENCES ACROSS ILEA TAKEN FROM FIVE HUMAN FOETUSES, FIVE CHILDREN, AND SEVEN ADULTS ${ }^{1}$

\begin{tabular}{|c|c|c|c|c|}
\hline \multirow{3}{*}{$\begin{array}{l}\text { Age } \\
\text { Foetus (wk) }\end{array}$} & \multicolumn{4}{|c|}{ Potential Difference $(\mathrm{mV})$} \\
\hline & \multirow{2}{*}{$\begin{array}{l}\text { Endo- } \\
\text { genous }\end{array}$} & \multirow{2}{*}{$\begin{array}{l}\text { Glucose } \\
\text { Transfer }\end{array}$} & \multicolumn{2}{|c|}{ Alanine Transfer } \\
\hline & & & L-alanine & D-alanine \\
\hline $14 \cdot 5$ & 0.6 & 0.9 & - & - \\
\hline 14.5 & $2 \cdot 1$ & $1 \cdot 3$ & 2.6 & -0.4 \\
\hline 15 & 0.5 & 1.4 & 2.6 & -0.3 \\
\hline 16.5 & 0.4 & 0.7 & - & - \\
\hline & $1 \cdot 6$ & $2 \cdot 0$ & $2 \cdot 7$ & - \\
\hline $\begin{array}{l}\text { Mean foetal } \\
\text { value } \pm \text { S.E. } \\
\text { Children }(0 \cdot 3-6 \cdot 5 \text { yr }) \\
\text { Adults }\end{array}$ & $\begin{array}{l}1.0 \pm 0.3 \\
4.0 \pm 0.8 \\
4.2 \pm 1\end{array}$ & $\begin{array}{l}1.3 \pm 0.2 \\
3.4 \pm 0.7\end{array}$ & $\frac{\bar{Z}}{2.6} \pm 0.7$ & $\begin{array}{c}\overline{-} \\
0.4 \pm 0.3\end{array}$ \\
\hline
\end{tabular}

${ }^{1}$ The glucose and amino acid transfer potentials across foetal ilea were obtained five minutes after the addition of the solutes $(7 \mathrm{mM}$ ) to the mucosal fluid and are uncorrected for osmotic effects. The data for the adult intestine are taken from Grady et al. (1966) and like the results from the children's ilea are expressed as the mean \pm S.E. The concentration of glucose and alanine used by these authors was $12 \mathrm{mM}$ and $20 \mathrm{mM}$ respectively.

The endogenous potential difference across foetal ileum was of the same order as that measured across the jejunum (Table II and Figure 2). The addition of glucose or L-alanine to the mucosal fluid again gave glucose or amino acid transfer potentials but Dalanine produced a small osmotic-induced potential. The ilea from children were incubated as quickly as possible after they had been removed and placed in cold bicarbonate saline. The interval between removal and incubation was usually 10 to 15 minutes. The amino acid transfer potential difference was measured in only one of these ilea. L-alanine ( $7 \mathrm{mM})$ increased the potential difference by $5.1 \mathrm{mV}$ while an identical addition of $D$-alanine caused no change in potential difference. 
DISCUSSION

THE FOETAL JEJUNUM The results obtained show conclusively that the addition of a number of hexoses and amino acids to the mucosal fluid bathing everted jejuna of the human foetus causes increases in the endogenous transmural potential difference, i.e. hexose or amino acid transfer potential differences are generated. The amino acid mechanism shows the typical specificity for the L-form previously noted in mature intestine of other animals (Schachter and Britten, 1961; Wilson, 1962; Levin, 1966) while the hexose mechanism appears specific for the actively transferred hexoses. The inference from these data is that by the twelfth week of gestation the jejunum of the human foetus has developed an electrogenic hexose and amino acid transfer mechanism.

The dose/response curves obtained for glucose show that the mechanism for the generation of the hexose transfer potential difference is a saturable one. In this context it is interesting to note that Sachar, Saha, and Hare (1967) have found that the potential difference generating mechanism in humans in vivo is saturated between 14 and $16 \mathrm{mM}$ glucose, a result that agrees remarkably well with the value of between 14 and $28 \mathrm{mM}$ for the foetal jejunum in vitro. Because the potential difference mechanism is saturable, the dose/response data can be made to fit Michaelis-Menten kinetics and 'apparent $\mathbf{K}_{\mathbf{m}} \mathbf{s}$ ' can be calculated by reciprocal plots of hexose potential against glucose concentration. Although such 'apparent $\mathrm{K}_{\mathrm{m}} \mathrm{s}$ ' cannot be more than a very crude estimate of the affinity of glucose for the generating site and objections can be raised against treating the data in this fashion, the method allows one to assess possible changes in affinity of the transfer mechanism during intestinal maturation. Values obtained for glucose by this method were of similar range, even though the jejuna from which they were obtained were of different ages, i.e. $5 \mathrm{mM}$ (14.5 weeks), $7.4 \mathrm{mM}$ (15 weeks), 1.2 $\mathrm{mM}$ (16.5 weeks), and $1.8 \mathrm{mM}$ (21 weeks). These compare well with 'apparent $\mathrm{K}_{\mathrm{m}} \mathrm{s}$ ' of 3 to $4 \mathrm{mM}$ found in embryonic and hatched chick (Hudson and Levin, 1966) and of $4 \mathrm{mM}$ for mature rat intestine (Asano, 1964). Lyon and Crane (1966) obtained a value of $0.87 \mathrm{mM}$ in jejuna from adult rats but they incubated the tissue in buffers of lower $\mathrm{NaCl}$ than normal.

The data in Fig. 2 show that the glucose transfer potential difference clearly increases with age of the foetus. This correlates well with the increase in glucose transfer with foetal age (Koldovský et al., 1965; Jirsová et al., 1966). It is possible, however, that such correlations between glucose transfer and the transfer potential difference are fortuitous. The magnitude of the transfer potential difference will depend not only on the pumping capacity of the active transfer mechanisms for ions but also on the passive permeability of the intestine. This permeability is a complex function of the cellular membranes and the intercellular leakage pathways. The former will be influenced by the developmental changes in the number and length of the microvilli of the intestinal cells observed in a number of animals (Overton and Shoup, 1964; Overton, 1965; Deren, Strauss, and Wilson, 1965), while the latter involves the functional tightness of the junctional complexes between mucosal cells. As only indirect data exist for possible changes in cell cohesion during intestinal development (Overton and Shoup, 1964) further discussion on this topic would not be useful. What is clear, however, is that to relate directly the magnitude of the hexose transfer potential with the magnitude of the active ion pump is dangerous unless either the resistance or the short circuit current of the intestine is also measured. Even if these are obtained, difficulties in interpretation will still exist, for the changing intestinal geometry during development means that some parameter will have to be found that will allow comparisons between intestines of widely differing anatomical complexity. The usual structural parameters like intestinal weight, protein or nitrogen content, will be of limited value in this context as they are a measure of all the cells, structures, etc., in the gut wall whether they are involved in transfer or otherwise. It is possible that functional parameters, such as the rate of diffusion of urea (Levin, 1967), will be a more useful basis upon which to place electrical measurements. Such problems, however, are for future studies. A number of the features of the endogenous and hexose transfer potential differences recorded across the foetal jejuna were similar to those previously recorded with intestine from mature animals. Phlorrhizin added to the mucosal fluid was found to block the action of glucose but did not affect the endogenous potential difference. The disaccharide sucrose supported a small transfer potential difference (presumably because of its hydrolysis to glucose and fructose) as has been observed in mature rat intestine (Kohn, Smyth, and Wright, 1966). It is interesting to note that lactose did not produce a transfer potential difference across the foetal jejunum. Dahlqvist and Lindberg (1966) recorded small amounts of lactase in human foetal intestine but it does not appear in quantity until the 28 th week of gestation. Thus any lactase in the jejunum from the $14 \cdot 5$-week foetus was unable to hydrolyse significant quantities of lactose to yield monosaccharide for the electrogenic hexose transfer mechanism. Anoxic conditions cause the potentials across the adult intestine in animals to fall rapidly, although there is evidence that in the 
presence of glucose the decrease is slowed (Barry et al., 1964). Anoxic conditions also affected the foetal endogenous potential difference more than that of glucose transfer potential difference. It thus appears that the foetal intestine can support the glucose transfer potential difference from energy obtained by anaerobic glycolysis of the glucose.

Lowering the mucosal sodium chloride concentration caused the small endogenous potential difference to reverse its sign (mucosa now becomes positive to serosa, Figure 3). This indicates that the pathways through which the $\mathrm{Na}^{+}$and $\mathrm{Cl}^{\prime}$ ions diffuse down the serosal to mucosal electrochemical concentration gradient allow $\mathrm{Na}$ ions through faster than $\mathrm{Cl}$ ions. Hence these pathways act as negatively charged pores. Similar results have been recorded for adult rat intestine (Wright, 1966) and hatched chick (Hudson and Levin, 1966). The hexose transfer potential difference generated by the addition of glucose at each level of lowered sodium chloride concentrations also gave results similar to that observed with the rat (Barry, Eggenton, Smyth, and Wright, 1966) and chick jejuna (Hudson and Levin, 1966). Lowering the mucosal sodium chloride concentration in three foetal jejuna did not reduce the hexose transfer potentials, in fact in two of the intestines they appear to be increased. This maintenance or increase in the hexose transfer potential difference may be due to changes in the conductivity of the intestinal wall. Asano (1964) recorded such changes in rat intestine when replacing sodium with choline, while Schultz, Curran, and Wright (1967) also found conductivity changes in rabbit ilea bathed with solutions of lowered $\mathrm{NaCl}$ concentration.

THE FOETAL ILEUM As glucose and alanine transfer potentials were observed across the foetal ileum this part of the intestine must also possess electrogenic hexose and amino acid transfer mechanisms, at least from week 14.5 of gestation. Thus, even though the foetal ileum has little ability to transfer glucose against a concentration gradient in vitro (Koldovský et al., 1965; Jirsová et al., 1966), the transfer mechanism does not appear to be qualitatively different from that of the jejunum. The results obtained with $D$ - and L-alanine also show that the specificity for the L-form is similar in both ileum and jejunum. Although there is a limited amount of information, the L-alanine transfer potentials appear to be higher than those observed across the jejunum, some $2 \cdot 6 \mathrm{mV}$ compared to approximately $1.1 \mathrm{mV}$. This is not observed when one compares the data for the glucose transfer potentials. Such differences between ileum and jejunum may be due to different affinities of the transfer mechanism for amino acids and glucose. A comparison of the foetal data with those obtained from children and adult ilea indicates that while the endogenous and glucose transfer potentials increase from foetal to adult life that of L-alanine remains similar. This suggests that specific changes occur in the development of the glucose as opposed to the amino acid transfer mechanism.

SPECIES DIFFERENCES IN THE DEVELOPMENT OF ELECTRICAL ACTIVITY ACROSS THE SMALL INTESTINE It is worthwhile to compare the results obtained with the human foetal intestine with those obtained with intestines from animal foetuses. Such comparisons may indicate the species that has an intestinal development (in regard to electrical activity) closest to man. In chick embryo three to four days before hatching ( 81 to $86 \%$ of the normal gestation period) the endogenous and glucose transfer potentials are high, approximately 22 and $12 \mathrm{mV}$ respectively, serosa positive to mucosa (Hudson and Levin, 1966). Both fall during embryonic and post-hatching development, reaching a basal level in the adult. Preliminary studies on small intestine from foetal, newborn, and adult rabbits (Levin, Koldovský, and Hošková, unpublished results) indicate that in this species the endogenous and glucose transfer potential difference increase during the maturation of the intestine from the foetus to the adult. Wright and Nixon (1961) found that the small intestine of foetal sheep had an endogenous potential difference of less than $3 \mathrm{mV}$ until the 120th day of gestation. After this time it increased to between 4 and $10 \mathrm{mV}$. In the 11 human foetuses studied in this paper the glucose transfer potential difference across the jejunum increases with foetal age but the endogenous potential difference does not show a similar trend. If the data from the ileum are used, however, there appears to be a distinct increase in the endogenous potential difference from the foetus to the child while that of adult ilea is of similar value to that of the children. Human foetal intestine is thus more like rabbit and sheep than like the chick in regard to the development of the electrical activity. Further studies are proceeding to explore more fully the developmental curves of the hexose and amino acid electrogenic pumps in the rabbit and chick intestine.

POSSIBLE ROLES FOR THE GLUCOSE AND AMINO ACIDS IN AMNIOTIC FLUID As both glucose (Schreiner and Gubler, 1963; Wood, Acharya, Cornwell, and Pinkerton, 1963) and amino acids (Wirtschafter, 1958) are present in amniotic fluid, and as this fluid is continuously swallowed by the foetus (McLain, 1963), it is possible that both solutes act as physiological inducers or substrates for the hexose and amino acid transfer systems in the small intestine. The correlation of the levels of these solutes in the 
amniotic fluid with the stages of development of the foetal alimentary tract would be of interest. Indeed, these levels might even be of future clinical value if high levels of amino acids and glucose correlate with oesophageal or duodenal atresia. The amino acids and glucose might also be implicated in other functions. The foetal intestinal tract is thought to play a role in the regulation of the volume of amniotic fluid (Mengert and Bourland, 1945). Actively transferred amino acids and glucose, by stimulating the transfer of sodium ions across the intestine (Schultz and Zalusky, 1965), could increase the absorption of fluid. The amino acids and glucose in amniotic fluid may thus have more complex functions than that of supplying nutrient for the foetus.

Acknowledgement is made to the British Council and the Czechoslovak Ministry of Education and Culture for financial support to R. J. Levin for travel and maintenance from the Programme of Cultural, Educational, Scientific and Technological Exchanges between Britain and Czechoslovakia 1966-68.

Dr. R. B. Zachary, of the Children's Hospital, Sheffield, kindly made available the ileal tissue removed from children undergoing intestinal operations, while Miss Janet Pratt undertook the in vitro experiments with this tissue.

\section{REFERENCES}

Asano, T. (1964). Metabolic disturbances and short-circuit current across intestinal wall of rat. Amer. J. Physiol., 207, 415-422.

Barry, R. J. C., Dikstein, S., Matthews, J., Smyth, D. H., and Wright, E. M. (1964). Electrical potentials associated with intestinal sugar transfer. J. Physiol. (Lond.), 171, 316-338.

- - Smyth, D. H., and Wright, E. M. (1965). Short-circuit current and solute transfer by rat jejunum. Ibid., 181, 410-431.

- Eggenton, J., Smyth, D. H., and Wright, E. M. (1966). Sodium concentration and hexose-dependent potentials in the small intestine. Ibid., 182, 40-41P.

Dahlqvist, A., and Lindberg, T. (1966). Development of the intestinal disaccharidase and alkaline phosphatase activities in the human foetus. Clin. Sci., 30, 517-528.

Deren, J. J., Strauss, E. W., and Wilson, T. H. (1965). The development of structure and transport systems of the fetal rabbit intestine. Develop. Biol., 12, 467-486.

Grady, G., MacGaffey, K., Moore, E. W., and Chalmers, T. C. (1966). Electrophysiological properties of human intestinal segments in vitro. (Abstr.) Gastroenterology, 50, 883.

Holdsworth, C. D., and Wilson, T. H. (1967). Development of active sugar and amino acid transport in the yolk sac and intestine of the chicken. Amer. J. Physiol., 212, 233-240.

Hudson, D. A., and Levin, R. J. (1966). Changes in the transmural potential difference associated with active hexose absorption during the development of the chick small intestine. J. Physiol. (Lond.), 186, 112-113P.
Jirsová, V., Koldovský, O., Heringová, A., Hošková, J., Jirásek, J. E., and Uher, J. (1966). The development of the functions of the small intestine of the human fetus. Biol. Neonat. (Basel), 9, 44-49.

Kohn, P. G., Smyth, D. H., and Wright, E. M. (1966). Effects of dipeptides and disaccharides on the electric potential across the rat small intestine. J. Physiol. (Lond.), 185, 47-48P.

Koldovský, O., Heringová, A., Jirsová, V., Jirásek, J. E., and Uher, J. (1965). Transport of glucose against a concentration gradient in everted sacs of jejunum and ileum of human fetuses. Gastroenterology, 48, 185-187.

Krebs, H. A. (1933). Untersuchungen über den Stoffwechsel der Aminosäuren im Tierkörper. Hoppe-Seylers Z. physiol. Chem., 217, 191-227.

Levin, R. J. (1966). Transmural potentials across the small and large intestine of the bullfrog, Rana catesbeiana. Proc. Soc. exp. Biol. (N.Y.), 121, 1033-1038.

- (1967). Techniques, terminology and parameters in intestinal absorption. Brit. med. Bull., 23, 209-212.

Lineweaver, H., and Burk, D. J. J. (1934). The determination of enzyme dissociation constants. J. Amer. chem. Soc., 56, 658-666.

Lyon, I., and Crane, R. K. (1966). Studies on transmural potentials in vitro in relation to intestinal absorption, I. Apparent Michaelis constants for Na-dependent sugar transport. Biochim. biophys. Acta (Amst.), 112, 278-291.

McLain, C. R., Jr. (1963). Amniography studies on the gastrointestinal motility of the human fetus. Amer.J. Obstet. Gynec., 86, 1079-1087.

Mengert, W. F., and Bourland, J. W. (1945). The circulation of amniotic fluid. Ibid., 50, 79-83.

Overton, J. (1965). Fine structure of the free cell surface in developing mouse intestinal mucosa. J. exp. Zool., 159, 195-201.

- and Shoup, J. (1964). Fine structure of cell surface specializations in the maturing duodenal mucosa of the chick. J. Cell Biol., 21, 75-85.

Potter, E. L. (1952). Pathology of the Fetus and the Newborn. Year Book Publishers, Chicago.

Sachar, D. B., Saha, J. R., and Hare, K. W. (1967). Transmural electric potentials and their response to sugars in the intestine of normal subjects and acute cholera patients. (Abstr.) Fed. Proc., 26, 384.

Schachter, D., and Britten, J. S. (1961). Active transport of nonelectrolytes and the potential gradients across intestinal segments in vitro. (Abstr.) Ibid., 20, 137.

Schreiner, W. E., and Gubler, A. (1963). Die Glukose und Milchsäurekonzentration im menschlichen Fruchtwasser während der normalen und pathologischen Schwangerschaft. $Z b l$. Gynäk., 85, 304-311.

Schultz, S. G., Curran, P. F., and Wright, E. M. (1967). Interpretation of hexose-dependent electrical potential differences in small intestine. Nature (Lond.), 214, 509-510.

_- and Zalusky, R. (1965). Interactions between active sodium transport and active amino-acid transport in the isolated rabbit ileum. Ibid., 205, 292-294.

Wilson, T. H. (1962). Intestinal Absorption, p. 118. Saunders, Philadelphia and London.

, and Lin, E. C. (1960). Active transport by intestines of fetal and newborn rabbits. Amer. J. Physiol., 199, 1030-1032.

Wirtschafter, Z. T. (1958). Free amino acids in human amniotic fluid, fetal and maternal serum. Amer. J. Obstet. Gynec., 76, 12191225.

Wood, C., Acharya, P. T., Cornwell, E., and Pinkerton, J. H. M. (1963). The significance of glucose and lactic acid concentration in the amniotic fluid. J. Obstet. Gynaec. Brit. Cwith, 70, 274-278.

Wright, E. M. (1966). Diffusion potentials across the small intestine. Nature (Lond.), 212, 189-190.

Wright, G. H., and Nixon, D. A. (1961). Absorption of amniotic fluid in the gut of foetal sheep. Ibid., 190, 816 . 